\title{
Commentary: Going the distance: The effect of margin length on local recurrence after wedge resection for colorectal metastases
}

\author{
Benjamin Wei, MD
}

From the Division of Cardiothoracic Surgery, University of Alabama-Birmingham Medical Center, Birmingham, Ala.

Disclosures: Author has nothing to disclose with regard to commercial support.

Received for publication Nov 8, 2018; accepted for publication Nov 8, 2018; available ahead of print Feb 13, 2019.

Address for reprints: Benjamin Wei, MD, Division of Cardiothoracic Surgery, Zeigler Research Building 707, 703

19th Street South, University of Alabama, Birmingham, AL 35294 (E-mail: bwei@uab.edu).

J Thorac Cardiovasc Surg 2019;157:1656-7

$0022-5223 / \$ 0.00$

Published by Elsevier Inc. on behalf of The American Association for Thoracic Surgery

https://doi.org/10.1016/j.jtcvs.2018.11.015

Nelson and colleagues, ${ }^{1}$ in their article "Surgical Margins and Risk of Local Recurrence After Wedge Resection of Colorectal Pulmonary Metastases," tackle a perennial question: How much of a margin is enough when performing pulmonary metastasectomy with curative intent? Their study analyzed a total of 679 wedge resections performed for colorectal lung metastases from 2006 to 2016 at a single academic medical center. Local recurrence was defined as a positive biopsy or enlarging nodule adjacent to the staple line; therefore, tissue diagnosis was not mandatory. Notably, $24 \%$ of the resections were performed without treatment of all sites of known disease and could therefore be termed "diagnostic" in intent. Interestingly, only $16 \%$ of the nodules were resected with video-assisted thoracoscopic surgery techniques. Patients were followed with cross-sectional imaging (computed tomography scan or positron emission tomography computed tomography scan) every 3 to 6 months. Unsurprisingly, the investigators found that the risk of local recurrence was associated with the size of the tumor nodule (2-year local recurrence rate of $8.8 \%$ for subcentimeter nodules, $12 \%$ for $1-2-\mathrm{cm}$ nodules, and $30.9 \%$ for $>2$-cm nodules). Longer margin length was also associated with a decreased risk of local recurrence (hazard ratio of 0.434 per additional centimeter of length; $P=.015)$. They estimated that achieving a margin length of at least half the tumor size resulted in a local recurrence risk of less than $11 \%$ within 2 years, a useful guideline that differs somewhat from the conventional wisdom that the ideal margin distance equals the diameter of the tumor.

Nelson and colleagues ${ }^{1}$ article is a beautiful example of how to conduct a highly focused retrospective study elegantly designed to answer a specific and limited question. It is duly noted, then, that their results should be applied only to colorectal metastases and not pulmonary metastasectomy in general. In addition, the study does not examine the impact that margin length has on patient

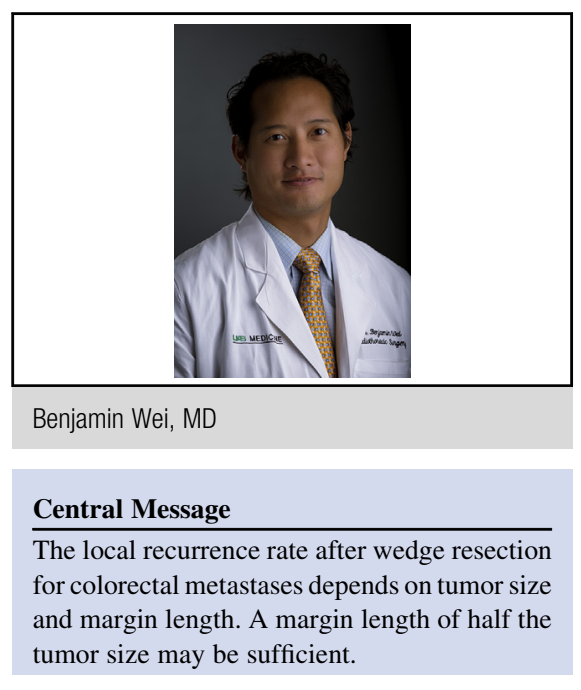

See Article page 1648.

survival. Digging deeper into their data, there remains a trend toward decreased recurrence risk with increased margin that is hard to ignore and somewhat difficult to reconcile with their central message: Local recurrence was $7.45 \%$ ( $1-\mathrm{cm}$ margin) versus $11.08 \%$ (0.5 margin) for $1-\mathrm{cm}$ tumors and $4.97 \%$ (2-cm margin) versus $11.09 \%$ (1-cm margin) for $2-\mathrm{cm}$ tumors. Therefore, the exhortation that achieving a margin distance of half the diameter of the tumor nodule is sufficient may be premature if we are to achieve the best results in our patients.

The fact that a $2-\mathrm{cm}$ margin on a $4-\mathrm{cm}$ tumor yielded an $11.11 \%$ local recurrence rate, however, does provide some justification for attempting to spare parenchyma even on relatively sizable metastases by performing a large wedge resection rather than a segmentectomy or lobectomy. However, this can be a dangerous road in an age when "less is more": The onus is on us as thoracic surgeons to achieve these margins and to continue to recognize the fact that for some lesions an anatomic resection may be the preferred option in the appropriately selected patient to optimize oncologic outcomes. ${ }^{2}$ Is an $11 \%$ local recurrence rate sufficient or can we do even better? Perhaps in the future, image guidance will play a role in the conduct of these operations by highlighting exactly how much lung to resect to achieve the desired margin distance. 
Pulmonary colorectal metastases have been found to have a high number of satellite tumor cells, which presumably are the origin of local recurrences. ${ }^{3}$ Given the effect of margin distance on local recurrence, one could extrapolate that surgical metastasectomy would be superior in this regard to stereotactic radiosurgery and other ablation techniques that are increasingly used for the same indications, because those therapies generally do not aim for more than a subcentimeter margin; however, no head-to-head, randomized comparison currently exists. $^{4,5}$ In the future, the question of margin distance may become overshadowed by the debate over these competing strategies used to manage pulmonary metastases.

\section{References}

1. Nelson DB, Tayob N, Mitchell KG, Correa AM, Hofstetter WL, Sepesi B, et al Surgical margins and risk of local recurrence after wedge resection of colorectal pulmonary metastases. J Thorac Cardiovasc Surg. 2019;157:1648-55.

2. Hernandez J, Molins L, Fibla JJ, Heras F, Embún R, Rivas JJ, et al. Role of major resection in pulmonary metastasectomy for colorectal cancer in the Spanish prospective multicenter study (GECMP-CCR). Ann Oncol. 2016;27:850-5.

3. Welter S, Theegarten D, Trarbach T, Maletzki F, Stamatis G, Tötsch M, et al Safety distance in the resection of colorectal lung metastases: a prospective evaluation of satellite tumor cells with immunohistochemistry. J Thorac Cardiovasc Surg. 2011;141:1218-22.

4. Helou J, Thibault I, Poon I. Stereotactic ablative radiation therapy for pulmonary metastases: histology, dose, and indication matter. Int J Radiat Oncol Biol Phys. 2017;98:419-27.

5. Palma DA, Olson RA, Harrow S, Gaede S, Louie AV, Haasbeek C, et al. Stereotactic ablative radiation therapy for the comprehensive treatment of oligometastatic tumors (SABR-COMET): results of a randomized trial. Int $J$ Radiat Oncol Biol Phys. 2018;102:S3-4. 